\title{
Psoriasis paradójica palmoplantar secundaria al tratamiento de la colitis ulcerosa con adalimumab
}

\section{Paradoxical psoriasis of the palms and soles due to treatment of ulcerative colitis with adalimumab}

\author{
Rashid Benítez Yazbek ${ }^{1}$, Lena Eimer ${ }^{2}$, Lucila Suar², Javier Anaya ${ }^{3}$ y Corina Busso ${ }^{4}$
}

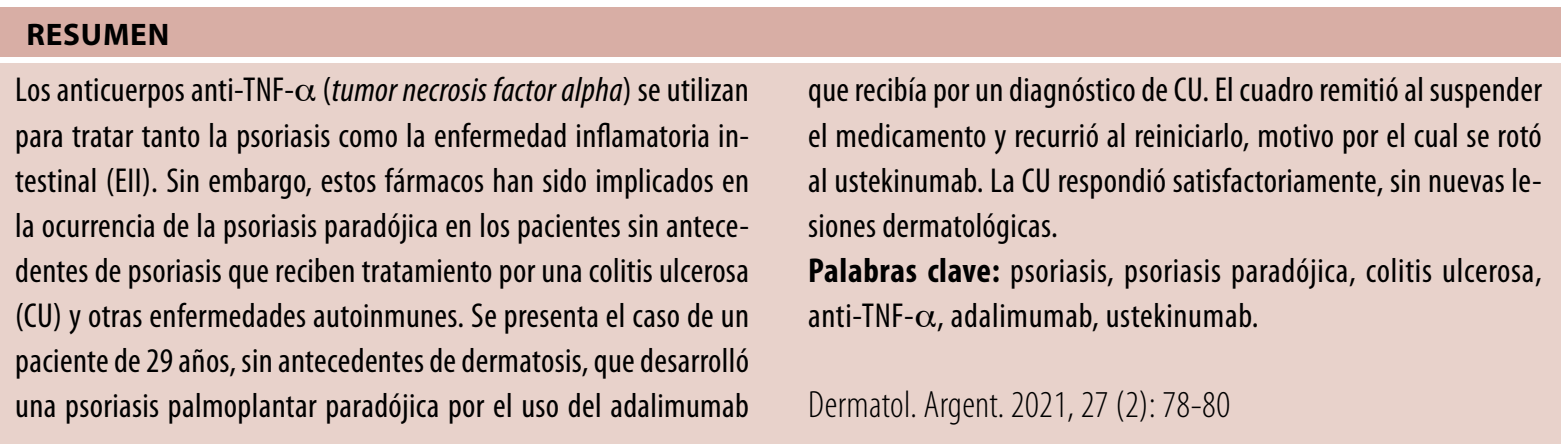

\section{ABSTRACT}

Anti TNF- $\alpha$ (tumor necrosis factor alpha) antibodies are used to treat both psoriasis and inflammatory bowel disease (IBD). However, these drugs have been implicated in the occurrence of the so-called paradoxical psoriasis in patients with no previous history of psoriasis, who receive treatment for ulcerative colitis and other autoimmune diseases. We present a 29-year-old male patient, with no previous history of dermatosis, who developed paradoxical palmar-plantar psoriasis due to the use of adalimumab that he was receiving for a diagnosis of ulcerative colitis. The condition remitted when the drug was suspended and recurred when it was restarted, and for that reason, treatment was rotated to ustekinumab. Ulcerative colitis responded satisfactorily, with no new dermatological lesions.

Kew words: psoriasis, paradoxical psoriasis, ulcerative colitis, antiTNF- $\alpha$, adalimumab, ustekinumab.

Dermatol. Argent. 2021, 27 (2): 78-80

\footnotetext{
1 Médico Residente

2 Médica de Planta. Especialista en Dermatología. Coordinadora de la Unidad de Psoriasis

${ }^{3}$ Médico de Planta de Anatomía Patológica

4 Jefa del Servicio

Servicios de Dermatología y Anatomía Patológica, Hospital Universitario Austral, Universidad Austral, Pilar, Provincia de Buenos Aires, Argentina
}

\section{CASO CLÍ́NICO}

Un varón de 29 años, con diagnóstico de CU y sin antecedentes de dermatosis, consultó por una erupción palmoplantar pruriginosa, de 7 días de evolución. Se encontraba afebril, en buen estado general, eutrófico. Negaba tabaquismo o consumo excesivo de alcohol y se desempeńaba como operario de maquinaria de envasado de harinas.

Por su enfermedad de base recibía adalimumab en dosis de $40 \mathrm{mg}$ por vía subcutánea cada 14 días, asociado a mesalazina $2 \mathrm{~g} / \mathrm{d}$ por vía oral desde hacía 2 años,
Contacto del autor: Rashid Benítez Yazbek

E-mail: rbyazbek@gmail.com

Fecha de trabajo recibido: $8 / 2 / 2021$

Fecha de trabajo aceptado: 16/6/2021

Conflicto de interés: los autores declaran que no existe conflicto de interés.

con buen control de la enfermedad, sin exacerbaciones en los últimos meses. En el examen físico presentaba placas eritematosas con descamación intensa, queratosis y fisuras dolorosas en las palmas y las plantas. No se observaban pústulas. Con el paso de los días, el paciente observó un empeoramiento progresivo de las lesiones acrales. Refería usar el equipo adecuado de protección en su trabajo y no había tenido contacto con sustancias irritantes (Foto 1). 


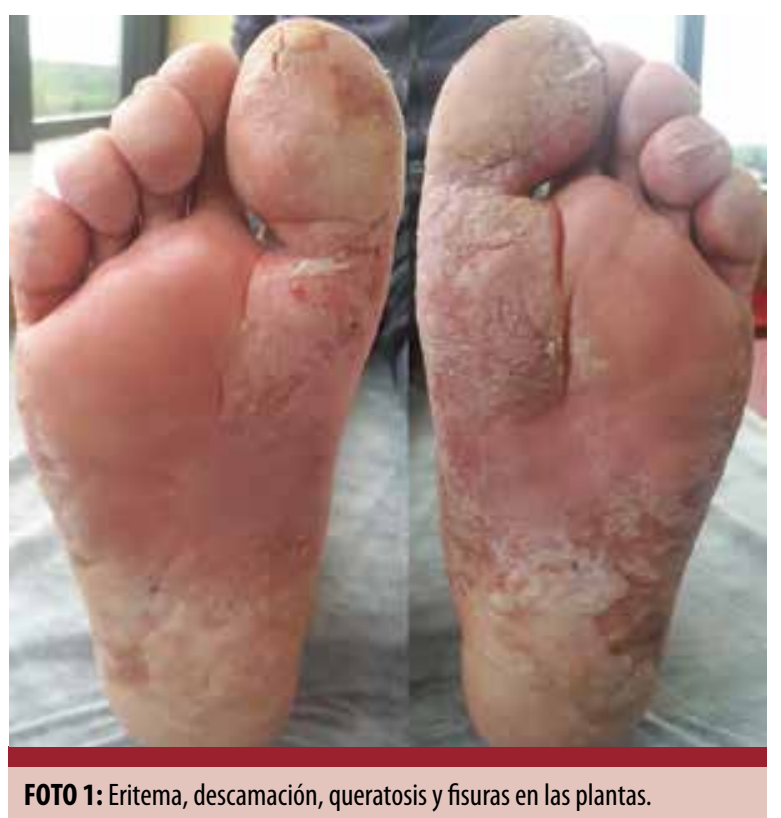

Se plantearon como diagnósticos diferenciales: dermatitis por contacto, eccema dishidrótico y psoriasis palmoplantar. Se realizaron biopsias de la palma derecha y la planta izquierda (Foto 2) y se indicó tratamiento tópico con clobetasol en ungüento más desloratadina $5 \mathrm{mg}$ por vía oral.

El estudio histopatológico reveló paraqueratosis, hiperplasia psoriasiforme y un infiltrado perivascular superficial mixto. Dada la sospecha de una reacción psoriasiforme secundaria a fármacos, sumada a la intensidad de la afección palmoplantar y a la incapacidad para realizar actividades cotidianas, se suspendió la siguiente dosis del adalimumab y se indicó tratamiento con mepredni-

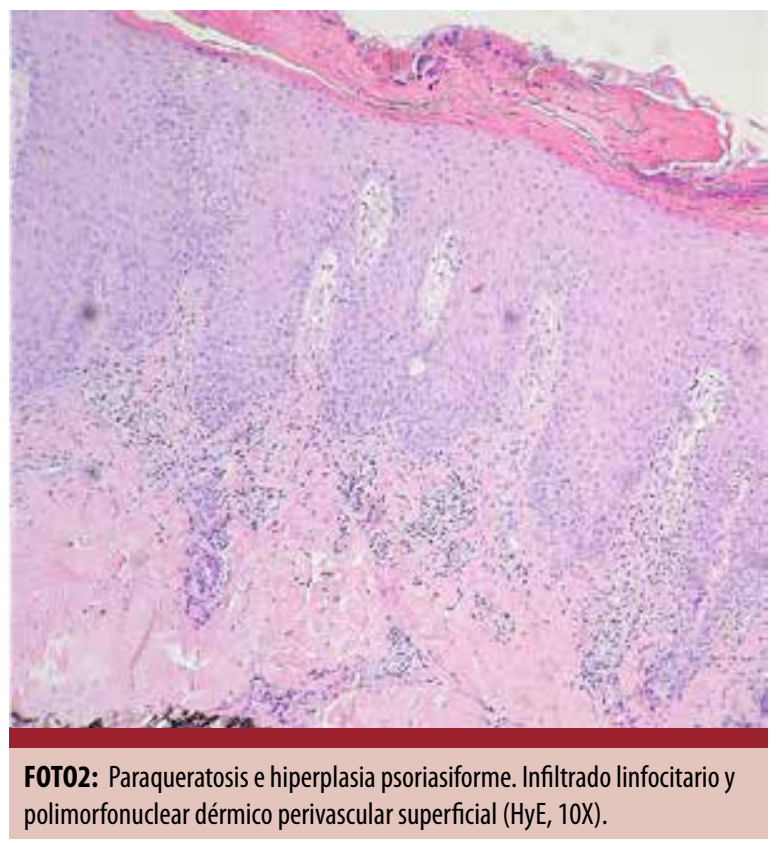

sona $16 \mathrm{mg} /$ día. En el transcurso de un mes, presentó una mejoría significativa de las lesiones en la piel, por lo que se suspendió la corticoterapia (previo descenso progresivo) y se reinició la terapia con el adalimumab.

A las 2 semanas de reinstaurado el tratamiento, evolucionó con un rebrote de mayor severidad en la misma localización, lo que confirmó el diagnóstico de psoriasis paradójica por el adalimumab, por lo que se lo suspendió de manera definitiva. En esta ocasión, se agregaron al cuadro diarrea y dolor abdominal, razón por la cual se realizó una videocolonoscopia, que mostró signos de actividad inflamatoria. Por ende, se reinició transitoriamente la corticoterapia con meprednisona $8 \mathrm{mg} /$ día.

Ante un paciente con CU activa de difícil manejo asociada a una psoriasis paradójica palmoplantar incapacitante por el adalimumab, se decidió rotar el agente biológico al ustekinumab, con una dosis de inducción de $380 \mathrm{mg}$ por vía intravenosa y, posteriormente, 90 mg subcutáneos cada 8 semanas. El resultado fue una remisión casi total de ambas patologías a los 3 meses (Foto 3) y se logró la suspensión de los corticosteroides orales, pero se mantuvo el tratamiento tópico.

Seis meses después, el paciente se encuentra en seguimiento por la Unidad de Psoriasis de nuestro hospital, con el mismo tratamiento y sin lesiones cutáneas.

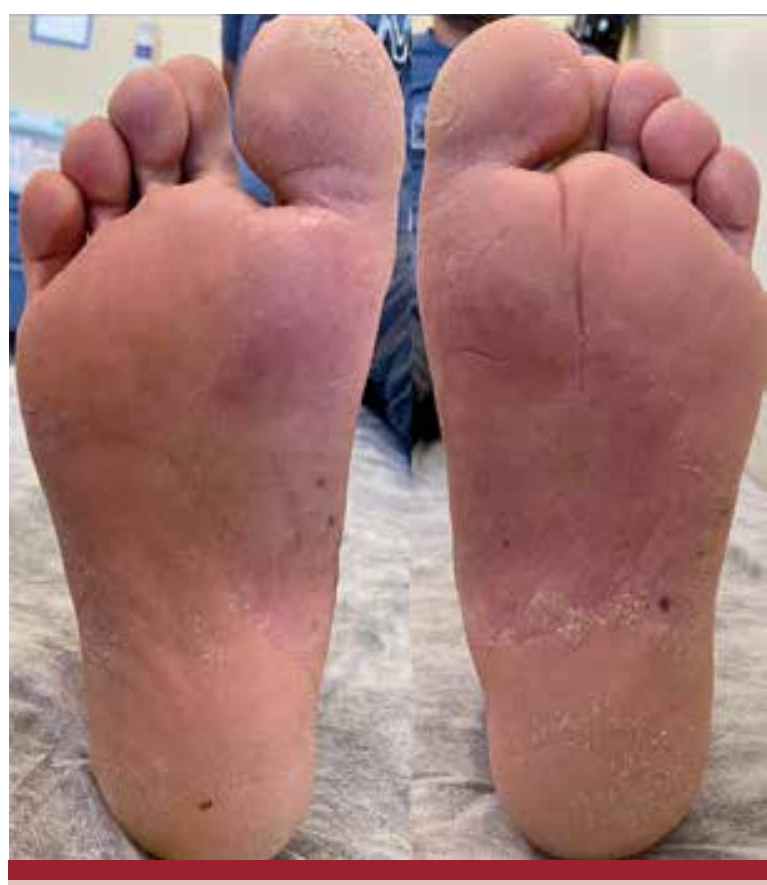

FOTO 3: Mejoría significativa de las lesiones en los pies tras el inicio del tratamiento con ustekinumab.

\section{COMENTARIO}

Algunos de los efectos adversos cutáneos del tratamiento con anticuerpos monoclonales anti-TNF- $\alpha$ incluyen las reacciones en el sitio de inyección, las infecciones, 
las reacciones de hipersensibilidad, la vasculitis leucocitoclástica, el síndrome de Steven-Johnson-necrólisis epidérmica tóxica y la psoriasis. En general, estos son leves y no requieren la discontinuación del fármaco, pero ante reacciones cutáneas severas puede ser necesario suspender el tratamiento ${ }^{1}$.

Si bien los anticuerpos anti-TNF- $\alpha$ se emplean para el tratamiento de la psoriasis moderada a severa, se ha demostrado que, paradójicamente, estos fármacos pueden inducir reacciones cutáneas psoriasiformes. Esto suele observarse en los pacientes que los reciben como tratamiento para otras patologías autoinmunes, como la artritis reumatoide, las espondiloartropatías seronegativas y la $\mathrm{EII}^{2}$.

De acuerdo con una revisión bibliográfica sistemática, que incluyó 207 casos de pacientes en tratamiento con distintos agentes anti-TNF- $\alpha$ por diversas patologías autoinmunes, la más frecuente la artritis reumatoide, la variante más frecuente de psoriasis paradójica era la pustulosa palmoplantar $(56 \%)$, seguida de la presentación en placas $(50 \%)$ y, menos a menudo, de la psoriasis en gotas o pequeñas placas (12\%); en algunos casos también se describieron formas superpuestas. No se encontraron diferencias en la incidencia de este efecto adverso según el sexo o la edad ${ }^{2}$.

Por otro lado, un estudio retrospectivo de 150 pacientes con antecedentes de EII (tanto enfermedad de Crohn como CU en tratamiento con infliximab, adalimumab o certolizumab pegol) halló que las localizaciones de afectación más frecuentes fueron las palmas y la plantas (43\%, sin especificar la presencia o la ausencia de pústulas) y el cuero cabelludo (42\%), seguidos del tronco $(32 \%)$ y los pliegues (31\%). En este estudio también se describieron formas clínicas superpuestas. Cabe destacar que en este último hubo un predominio de afectación en las mujeres ${ }^{3}$.

La mayoría de estos pacientes no tienen antecedentes personales ni familiares de psoriasis. Se identificaron el tabaquismo y el sobrepeso como factores de riesgo asociados a la aparición de lesiones psoriasiformes en los pacientes con EII que reciben tratamiento con anticuerpos

\section{BIBLIOGRAFÍA}

1. Lindhaus C, Tittelbach J, Elsner P. Cutaneous side effects of TNFalpha inhibitors. J Dtsch Dermatol Ges. 2017;15:281-288.

2. Collamer AN, Battafarano DF. Psoriatic skin lesions induced by tumor necrosis factor antagonist therapy: clinical features and possible immunopathogenesis. Semin Arthritis Rheum. 2010;40:233-240.

3. Cullen G, Kroshinsky D, Cheifetz AS, KorzenikJR. Psoriasis associated with anti-tumour necrosis factor therapy in inflammatory bowel disease: a new series and a review of 120 cases from the literature. Aliment Pharmacol Ther. 2011;34:1318-1327.

4. Tillack C, Ehmann LM, Friedrich M, Laubender RP, et ál. Anti-TNF antibody-induced psoriasiform skin lesions in patients with inflammatory bowel disease are characterized by interferon- $\gamma$ expressing Th1 cells and IL-17A/LL-22-expressing Th17 cells and respond to anti-IL-12/IL-23 antibody treatment. Gut. 2014;63:567-577.
anti-TNF- $\alpha^{4}$. También se comunicó el efecto inverso: el desarrollo de enfermedad de Crohn o de CU "paradójica" en pacientes que se encontraban en tratamiento con este grupo de fármacos por una psoriasis moderada a severa 5 .

La fisiopatogenia de la psoriasis paradójica se desconoce. Se propone el aumento de la expresión de IFN- $\alpha$ como respuesta a la desregulación de citoquinas producida por la inhibición del TNF- $\alpha$ en individuos genéticamente predispuestos, junto con un marcado infiltrado de linfocitos Th17 y Th1 que expresan IL-17/22 e interferón gamma, respectivamente, los cuales reproducen el perfil de lo encontrado en las placas de psoriasis originales. La severidad de la reacción cutánea parece depender de la densidad de la infiltración por las células Th1 $17^{2-4}$.

El enfoque terapéutico en estos casos se basa en los tratamientos convencionales para la psoriasis, como corticosteroides tópicos, emolientes, queratolíticos, metotrexato o fototerapia. Por lo general, se logra el control del cuadro cutáneo sin necesidad de suspender el anti-TNF- $\alpha$, pero existen casos cuya severidad requiere la suspensión definitiva y el cambio del tratamiento por un fármaco con distinto mecanismo de acción ${ }^{6,7}$.

En el paciente del caso analizado, optamos por rotar el tratamiento al ustekinumab, un agente biológico que interfiere en la función de las IL-12 y 23, que abarca ambas patologías (aprobado en septiembre de 2019 por la Comisión Europea para el tratamiento de la CU moderada a severa), con excelente respuesta. Los inhibidores de la IL-17, como el secukinumab, no se recomiendan por la posibilidad de exacerbar la EII ${ }^{8}$.

Se presenta un caso de psoriasis paradójica palmoplantar severa como efecto adverso cutáneo del tratamiento con adalimumab, con excelente respuesta clínica al rotar el tratamiento al ustekinumab.

\section{Agradecimiento}

Al Dr. Germán Rainero, médico gastroenterólogo de planta del Hospital Universitario Austral, con quien realizamos el tratamiento y seguimiento del paciente.

5. Kolios AGA, Biedermann L, Weber A, Navarini AA, et ál. Paradoxical ulcerative colitis during adalimumab treatment of psoriasis resolved by switch to ustekinumab. Br J Dermatol. 2018;178:551-555.

6. Rahier JF, Buche S, Peyrin-Biroulet L, Bouhnik Y, et ál. Severe skin lesions cause patients with inflammatory bowel disease to discontinue anti-tumor necrosis factor therapy. Clin Gastroenterol Hepatol. 2010;8:1048-1055.

7. Whitlock SM, Enos CW, Armstrong AW, Gottlieb A, et ál. Management of psoriasis in patients with inflammatory bowel disease: From the Medical Board of the National Psoriasis Foundation. J Am Acad Dermatol. 2018;78:383-394.

8. Cohen AD, Dreiher J, Birkenfeld S. Psoriasis associated with ulcerative colitis and Crohn's disease. J Eur Acad Dermatol Venereol. 2009;23:561-565 